Lifa Ainur Rahmah

\title{
KONTRIBUSI PANCASILA DI KANCAH INTERNASIONAL: Eksplorasi Nilai-Nilai Perdamaian Qur'ani Dari Bingkai Keindonesiaan
}

\author{
Sekolah Tinggi Agama Islam Al Fithrah, Surabaya \\ E-mail: lifaa180@gmail.com
}

Received:

2020-03-21

Received in revised form:

2020-04-29

\section{Accepted:}

2020-06-26

\section{Citation:}

Rahmah, Lifa Ainur, (2020),

Kontribusi Pancasila Di

Kancah Internasional:

Eksplorasi Nilai-Nilai

Perdamaian Qur'ani Dari

Bingkai Keindonesiaan, 7(1), 62-85.

\begin{abstract}
Issues regarding peace issues and conflicts are always heavily discussed. Not surprisingly, there are many events that are oriented to reestablishing peace and harmony. Indonesia with the largest Muslim population, remains known as a peaceful residence and can manage diversity. The proof, it is not Islam that is used as an ideology, but Pancasila. But this ideology is rich in noble values that strengthen the solidarity of Indonesian people. In this article, the author tries to explore the values of peace and harmony that read the verses of the Qur'an from the life of the Indonesian people. The trident ethos in Pancasila is the focus of the review of this article. Besides Pancasila is Indonesia's ideology, a country that has an important role in peace in the international world, another reason for the author is that Pancasila is inseparable from the spirit of Islam, a religion of moderate character.
\end{abstract}

Keywords: Peace, Pancasila, Interpretation, and Qur'an. 


\begin{abstract}
Abstrak: Persoalan mengenai isu-isu dan konflik perdamaian senantiasa ramai diperbincangkan. Tidak mengherankan, banyak ditemukan berbagai event yang berorientasi dalam mengokobkan kembali sebuah perdamaian dan harmonisasi. Indonesia dengan penduduk. Islam terbanyak, tetap dikenal sebagai tempat tinggal yang damai dan dapat mengelola keberagaman. Buktinya, bukan Islam yang dijadikan ideologi, melainkan Pancasila. Namun ideologi ini kaya dengan nilai-nilai lubur yang memperkuat solidaritas manusia Indonesia. Dalam artikel ini, penulis berusaba mengeksplorasi nilai-nilai perdamaian dan harmonisasi yang berbunyi ayat Al-Qur"an dari kehidupan bangsa Indonesia. Etos trisila dalamPancasila menjadi fokus kajian artikel ini. Di samping Pancasila adalah ideologi Indonesia, negara yang memiliki peran penting dalam perdamaian di dunia international, alasan lain bagi penulis ialah bahwa Pancasila tidak terlepas dari roh Islam, sebuah agama yang berkarakter moderat.
\end{abstract}

Kata Kunci: Perdamaian, Pancasila, Tafsir dan Al-Qur'an.

\title{
PENDAHULUAN
}

Bagi suatu negara, ideologi merupakan sesuatu yang bersifat fundemental. Sesuatu yang bersifat urgen, karena harus menjadi mata angin bagi tersusunnya perundang-undangan di dalam negara tersebut. Menjadi arah mata angin terhadap aturan-aturan yang hendak dibentuk. Fenomena ini menjadi bukti, gerak-aktivitas negara berdiri di atas dasar negara itu sendiri. ${ }^{1}$

Negara yang biasa disebut sebagai negara Pancasila, Indonesia tidak bisa dipisahkan dengan Pancasila yang menjadi ideologi di dalamnya. Ideologi bagi sebuah bangsa bukan hanya menjadi identitas, melainkan representasi dari seluruh keberagaman di dalam sebuah Negara. Notonagoro berpendapat, Pancasila adalah hasil pemikiran yang mendalam. Bukan sekedar hasil analisis, ia merupakan buah pemikiran yang mendalam yang tidak bisa digapai oleh sembarang orang. Pancasila tidak lahir dalam satu kali kecapan lisan, atau diucapkan secara spontan. Ideologi Indonesia merdeka ini dipikirkan secara mendalam dan bertahun-tahun lamanya, karena di dalamnya ia harus memuat nilai-nilai filosofi. Dalam hal ini, apa yang timbul dari sidang BPUPKI 1 Juni 1945, Bung Karno telah memenuhi syarat-syarat kefilsafatan dalam mengusulkan

\footnotetext{
${ }^{1}$ Afkar, Kritik Ideologi Radikal, (cet. 1, Kediri: Lirboyo Press, 2018), 401.
} 
Pancasila sebagai ideologi negaranya. Antara lain melakukan deskripsi, berpikir yang kritik, evaluasi dan abstraksi. ${ }^{2}$

Secara etimologi, pancasila merupakan gabungan dari Panca dan sila. Panca artinya lima. Sila atau syila bermakna sendi atau batu dasar. Kata sila juga berasal dari kata susila yang berarti tingkah laku yang baik. Dari sini, pancasila berarti lima sendi atau pancasila adalah lima tingkah laku yang baik. ${ }^{3}$

Secara terminologi, Pancasila lahir dari sidang BPUPKI saat Bung Karno menggunakan istilah Pancasila untuk menamai lima prinsip dasar negara ${ }^{4}$ pada 1 Juni 1945. 1 Juni 1945 biasa juga disebut sebagai hari Pancasila. Mengingat lima dasar yang kemudian dimatangkan kembali oleh Panitia Sembilan hingga 22 Juni 1945. Hingga mencapai hari proklamasi digelar, isi sila pertama kerap menuai perdebatan dan keberatan. Sila pertama yang semula berbunyi "Ketuhanan dengan kewajiban menjalankan syari'at Islam bagi pemeluk-pemeluknya" masih rekat di tubuh pancasila. Hingga sehari setelah proklamasi yakni 18 Agustus 1945, sila pertama tersebut diganti dengan bunyi sila pertama yang terus digemakan hingga hari ini. ${ }^{5}$

Secara praktis, Pancasila tidak lepas dari napas-napas Islam karena tokohtokoh yang terlibat dalam perumusan Pancasila juga meliputi tokoh-tokoh Islam. Di antaranya K.H.A. Wahid Hasyim, K.H. Mas Mansyur, Abdul Kahal Muzakir dan selainnya. Tokoh-tokoh di atas, bukan hanya terlibat dalam sidang BPUPKI,

\footnotetext{
2 Sunoto, Mengenal Filsafat Pancasila, (Yogyakarta: Hanindita Graha Widya,1995),55.

3 Tim Penyusun MKD IAIN Sunan Ampel, Pancasila dan Kewarganegaraan (Surabaya: UIN Sunan Ampel Press, 2013), 10.

4 Menurut beberapa catatan sejarah, mulanya lima prinsip negara tersebut hendak dinamai "Panca Dharma". Namun kemudian, (menurut catatan sejarah yang dirunut) ahli bahasa menyarankan agar "Panca Dharma" baiknya diganti dengan "Panca Sila". Karena Dharma artinya kewajiban, sementara Sila berarti azas atau dasar. Dari sini, Pancasila lebih tepat dicomot sebagai istilah penamaan lima prinsip dasar negara. Kutipan ini biasa dikutip dalam rangka menyirat-menyuratkan bahwa pancasila bukan ideologi yang timbul secara spontan. Yang timbul dalam satu kali pernyataan lisan. Melainkan, ia (pancasila) timbul dari hasil perenungan jiwa yang sangat dalam. Lihat Sunoto, Mengenal Filsafat Pancasila, 54.

${ }^{5}$ Afkar, Kritik Ideologi Radikal, 404-405.

At-Turäs: Jurnal Studi Keislaman

E-ISSN: 2460-1063, P-ISSN: 2355-567X

Volume 7, No. 1, Januari-Juni 2020
} 
tokoh- tokoh Islam tersebut juga menjadi anggota panitia sembilan. Hal ini seperti menjadi indikasi, bahwa Pancasila tidak lepas dari roh Islam. Bahkan, yang mengusulkan tambahan "Yang Maha Esa" dalam sila pertama ialah K.H.A. Wahid Hasyim. Menurutnya, hal ini merupakan suatu rumusan yang berimplikasi Tauhid bagi umat Islam. ${ }^{6}$

Para tokoh di masa lalu memberikan rumusan yang berbeda untuk dasar negara. Hal ini dikarenakan tokoh yang merumuskan berasal dari beberapa etnis yang berbeda, yang kemudian terkelompok menjadi kaum nasionalis dan kaum agamis. Hal ini tentu tidak terlepas karena kemajemukan di dalamnya.

Pancasila sebagai wujud kesepakatan nasional, merupakan hasil eksplorasi nilai yang bersumber dari adat-istiadat, budaya, keberagaman, pemikiran, dan pandangan hidup seluruh komponen bangsa yang hidup di atas bumi Nusantara meliputi kemajemukan dalam suku, ras, agama dan antar golongan (SARA). ${ }^{7}$ Dari sini, bisa ditarik kesimpulan, bahwa ideologi Pancasila yang mengusung keanekaragaman di dalamnya bisa dan pantas dihadapkan pada ideologi dunia. Pancasila bisa terus berjalan dengan keanekaragamannya tanpa perlu diseragamkan.

Keberagaman di Indonesia, mencakup nilai-nilai luhur yang lahir melalui nilai-nilai lima sila. Yakni: ketuhanan, kemanusiaan, persatuan, kerakyatan, dan keadilan. Lima sila ini digali dan dihasilkan oleh bangsa Indonesia dan bisa dihadapkan dengan ideologi lain di dunia.

Dalam artikel ini, sebagai upaya mewujudkan perdamaian, penulis ingin mengeksplorasi nilai-nilai pancasila, melalui Al-Qur'an beserta tafsirnya. Di samping sebagai ideologi yang pantas dihadirkan di kancah Internasional, fakta sejarah pun menyatakan bahwa Islam damai adalah Islam Indonesia. Dari sini,

7 Tim Penyusun MKD IAIN Sunan Ampel, Pancasila dan Kewarganegaraan, 163. 
penulis ingin melakukan pembacaan ayat Al-Qur"an yang bersentuhan dengan nilai-nilai Pancasila, terutama hal-hal yang berafiliasi dengan perdamaian dan keharmonisan.

\section{PEMBAHASAN \\ INDONESIA DAN PERDAMAIAN INTERNASIONAL: TANTANGAN DAN PELUANG}

Secara konsepsi, semua orang, meliputi tokoh agama dan adat, tentu mengharapkan damai, kedamaian, dan perdamaian. Damai diartikan berbedabeda. Tergantung konteks dan pengucapnya. Kata damai juga dikonsepsikan sebagai suatu ketenangan, seperti terbebas dari suatu kebisingan. Dengan begitu, ketidakadilan juga merupakan bentuk dari lawan kata damai. Damai adalah lawan dari perang, kerusuhan, dan yang semakna dengan kondisi hilangnya rasa damai. ${ }^{8}$ Damai juga diartikan sebagai lawan kata intoleran.

Faktor intoleran, setidak-tidaknya dapat ditilik dari tiga hal. Pertama, hilangnya sikap toleran terjadi di kalangan sesama pemeluk agama. ${ }^{9}$ Hal ini lumrahnya terjadi karena perbedaan sudut pandang dalam hal menafsiri nashnash syar ${ }^{\mathrm{e}} \mathrm{i}$, semisal dalam konteks Islam. ${ }^{10}$

Kedua, fenomena damai juga gagal diaplikasikan karena hilangnya toleransi di kalangan antar umat beragama. Berbicara soal lintas agama, pembaca dinamika sosial hampir selalu dihadapkan pada hilangnya harmonisasi antara satu pemeluk agama dengan pemeluk agama lain. beberapa kasus antar agama yang mengemuka misalnya yang terjadi di Ambon dan Poso. Di sana, terjadi penutupan gereja dibeberapa daerah dengan dalih bahwa gereja tersebut ilegal. Karena gereja tersebut berdiri di atas tanah yang seharusnya

\footnotetext{
${ }^{8}$ Khamami Zada, dkk, Prakarsa Perdamaian: Pengalaman Dari Berbagai Konflik Sosial Kapital, (Jakarta: PP Lakpesdam NU, 2008), 98.

${ }^{9}$ Ibid., 3.

${ }^{10}$ Wahbahal-Zuhaili,al-Fiqhal-Islamiwna Adillatuh,vol1 (cet.4,Damaskus:Daral-Fikr,t.th),64. 
dijadikan tempat tinggal atau ruko. ${ }^{11}$

Ketiga, hilangnya toleransi dari sikap kelompok-kelompok agama terhadap adat dan kebudayaan asli. Terutama terhadap adat masyarakat yang telah berakulturasi ${ }^{12}$ dengan agama. Fenomena adat demikian seringkali dianggap sebagai agama sinkretis dan telah keluar dari jalan agama yang benar. Faktor agama dan budaya bahkan merupakan satu faktor yang banyak menarik perhatian, karena kerapkali konfliknya berujung pada tindak kekerasan. ${ }^{13}$

"Kerukunan hidup dan saling menyelamatkan pada dasarnya merupakan cita- cita bersama bagi umat beragama di dunia. Dengan kata lain, ide dasar cita-cita itu dimiliki oleh masing-masing agama. Namun dalam aktualisasinya ketika sebuah agama berdialektika dengan agama lain, menggiring pada kesimpulan ekstrim bahwa agama tidak lagi mampu melahirkan masyarakat yang harmonis, apalagi kreatif sebagaimana dasar cita-cita agama. Hal ini terbukti dengan makin meluasnya konflik- konflik antar-intra agama dan masyarakat yang meliputi pelaku, intensitas, waktu maupun geografisnya."14

Sebagaimana statement di atas, beberapa fakta telah disajikan di sebagian negara yang mengabadikan kekerasan sebagai akhir konflik. Menurut orangorang yang berpandangan demikian, mereka hanya menawarkan satu pilihan berupa pembunuhan. Selanjutnya, mereka akan dihadapkan pada satu pilihan sempit dibunuh, atau membunuh. Sampai hari ini, Iran, Irak, Lebanon dan

${ }^{11}$ Khamami Zada, dkk, Prakarsa Perdamaian: Pengalaman Dari Berbagai Konflik Sosial Kapital, 4.

12 Terdapat dua pola kata yang nampak sama, namun berbeda pengertian, yaitu akulturasi dan asimilasi. Akulturasi dapat diartikan sebagai penggabungan budaya dan agama. Namun tidak bersifat melebur. Artinya, tidak sampai pada taraf dinamai agama baru, hanya saja budaya ada di sub ordinasi daripada agama. Produk akulturasi yang demikian, dinamai Islam populis. Seperti ajaran tahlil yang semula berasal dari budaya cangkruk(an) atau begadang dalam melakukan hal yang tidak bermanfaat bahkan diharamkan seusai wafatnya seseorang. Sementara jika sebaliknya, ia dinamakan sinkretis. Contoh sinkretis adalah realita ajaran di Sasak Lombok yang mengajarkan sholat hanya di tiga waktu. Berbeda dengan asimilasi, di mana agama dan budaya bercampur, bahkan melebur menjadi agama baru. Lihat Hamzah Junaid, "Kajian Kritis Akulturasi Islam Dengan Budaya Lokal", Sulesana 8, No. 1 (2013), 9. Dan "Islam Nusantara: Akulturasi Islam dan Budaya Lokal". Hikam.id, terakhir dipost September 24, 2019, https://hikamadress99.blogspot.com/2019/09/islamnusantara-akulturasi-islam-dan.html

${ }^{13}$ Khamami Zada, dkk, Prakarsa Perdamaian: Pengalaman Dari Berbagai Konflik Sosial Kapital, 4.

${ }^{14}$ Chafid Wahyudi, "Etika Publik Sebagai Ruang Dialog Agama”, HIKMATUNA 1, No. 1 (2015), 36-37. 
Suriah masih bertikai sengit. Bertikai antar sesama, ${ }^{15}$ yang sampai hari ini terus bersitegang mempertahankan paradigma-paradigma kebenaran yang dianut masing-masing kelompok. Kekerasan terus bergulir karena faktor lebih mengedepankan monolog, dan mendiskreditkan dialog.

Dalam banyak literatur kajian, Indonesia diakui sebagai negara yang mengisi urutan terdepan dalam hal mengusung nilai-nilai perdamaian. Menjadi cerminan bagi negara lain, utamanya soal konsep damai yang ditawarkan negeri pancasila. Karena Indonesia berpotensi besar menjadi salah satu magnit dunia dalam dimensi demografis-geospritiual. Wajah Indonesia yang berbasis religi bisa dikatakan unik. Karena jumlah penduduknya yang mayoritas memeluk Islam namun memposisikan kerukunan sebagai prioritas utama. ${ }^{16}$

Sebagai bangsa yang hidup dengan segala keragaman, tentu saja bangsa yang berideologikan Pancasila harus siap dengan perbedaan sikap atau pikiran orang sebangsa tapi tak sepemikiran. Kemajemukan di Indonesia sebagaimana diketahui terdiri atas sosial, budaya, agama, dan lain sebagainya. Pluralitas adalah sunatullah, keragaman merupakan relaitas yang tak terbantahkan. Pluralitas dan keragaman- sosial, budaya, politik, maupun agama-dalam masyarakat merupakan kekayaan suatu bangsa. Namun, di samping bernilai positif, pluralitas juga dapat berdampak negatif jika tidak dapat dikelola dengan baik. ${ }^{17}$ Kendatipun keberagaman menjadi tantangan tersendiri bagi negeri Pancasila, ia juga tidak dapat dipisahkan dari peluang besar yang membuatnya gagah di hadapan ideologi lain di dunia.

Semboyan Bhineka Tunggal Ika, Ideologi Pancasila, dan tidak

\footnotetext{
${ }^{15}$ Ren Muhammad, "Islam Tanpa Indonesia", alif.id, terakhir dipost Juli 08, 2019, https://alif.id/read/ren-muhammad/islam-tanpa-indonesia-b220816p/

16 Alwi Shihab, Islam dan Kebbinekaan, (Jakarta: Gramedia Pustaka Utama, t.th), vi.

${ }^{17}$ Abdul Rozak, "Komunikasi Lintas Agama: Modal Sosial Pembentukan Masyarakat Sipil”, JURNAL $D A K W A H$, Vol. 9., No. 1 (2008), 24.
} 
mengusung negeri khilafah adalah bukti konkrit bahwa NKRI mampu mengelola keragaman yang ada di dalamnya dengan baik. Tanpa mendiskreditkan minoritas atau menjunjung mayoritas. Karena faktor tersebut, Indonesia menjadi cermin damai di kancah internasional. Hal ini terbukti ketika ulama kenamaan asal Indonesia, ahli tafsir Al Qur"an diundang ke Abu Dhabi, Uni Emirat Arab. Quraish Shihab hadir bersama Imam Besar Al Azhar, Dr. Ahmed Al-Tayeb dan Paus Fransiskus yang menyerahkan "Dokumen Persaudaraan Manusia untuk Perdamaian Dunia dan Hidup Berdampingan". Quraish Shihab hadir dalam kapasitas sebagai anggota Majlis Hukamae Al Islam $^{18}$ atau dewan tetua Muslim (Majelis orang-orang Bijak Muslim) dan memberi ceramah dalam deklarasi persaudaraan manusia untuk pembangunan dunia tersebut dengan tema "Persaudaraan Manusia: Tantangan dan Kesempatan." 19

Sebagai cerminan di mata dunia, tidak sedikit yang berusaha menelisik akar pola hidup manusia Indonesia. Menurut penduduk dalam negeri, bangsa Indonesia akan kehilangan jiwanya, tanpa adanya Pancasila. Memang, Pancasila dilansir sebagai jiwa seluruh rakyat Indonesia. ${ }^{20}$ Di samping dapat mengelola keragaman manusia Indonesia, misi besar ideologi ini tentang kesatuan dan persatuan bangsa, mendorong dunia International tertarik mengonsumsi model perdamaian dan keharmonisan yang dijunjung negara Pancasila. Menurut hemat

18 Organisasi ini didirikan oleh dua belas orang yang dari berbagai negara Muslim. Di antaranya: Mesir, Marokom Tunisia, Uni Emirat Arab, Nigeria, dan Indonesia. Dipimpin oleh Dr. Ahmad al-Thayib dari Mesir, seorang mantan mufti dan mantan rektor di Mesir yang kini menjadi Pemimpin Tertinggi Lembaga-Lembaga AlAzhar Mesir. Majlis ini didirikan dengan tujuan mampu mengajak dan memperjuangkan betul penghindaran kekerasan apapun bentuknya. Mendahulukan dialog dengan penegasan, perbedaan harus dihormati meski tidak bisa diterima. Harus dihormati selama pendapat tersebut bercirikan kedamaian. Lihat "Majelis al-Hukama", quraishshihab.com, terakhir dipost November 25, 2019, https://quraishshihab.com/article/majlis-al-hukama/

19 Alvin Nur Choironi, "Quraish Shihab Hadiri Deklarasi Abu Dhabi Bersama Syekh Al Azhar dan Paus Fransiskus”, islami.co, terakhir dipost Februari 06, 2019, https://islami.co/quraish-shihab-hadiri-deklarasi-abudhabi-bersama-syekh-al-azhar-dan-paus-fransiskus/

20 Sunoto, Mengenal Filsafat Pancasila, 98. 
penulis, Pancasila dan konsep damai adalah satu paket lengkap yang memuat perdamaian dan memukul mundur semua yang berlawanan dengan konsep damai itu sendiri.

\section{MODERAT DAN KESEIMBANGAN SEBAGAI KARAKTER ISLAM}

Berdasarkan karakter pedoman utama yang dianuti di setiap keyakinan, Islam adalah sebuah agama atau ruang perjalanan yang sempurna. Al-Qur"an yang dikenaldengan kemukjizatannya yang sempurna dan Sunnah yang merupakan segala laku Rasulullah SAW, manusia yang paling sempurna, mengindikasikan Islam memiliki banyak keistimewahan. Al-Qur"an sebagai salah satu sumber pokok umat Islam, merupakan kitab suci atau kalam Allah Ta"ala yang kandungannya termuat dasar-dasar yang selalu mengajak kepada keadilan dankedamaian. ${ }^{21}$

Jika ditelusuri kembali dalam Al-Qur"an dan Sunnah, sebenarnya Islam adalah agama yang moderat. Hampir seluruh para intelektual Islam mengkauinya. Hanya karena kelemahan akal manusia yang terbatas, banyak tindakan atau aksi dari mereka yang terlihat ekstrem, dengan disadari ataupun tidak. Tidak mengherankan, realitas menunjukkan sebuah perselisihan antara beberapa wajah Islam yang saling ditabrakkan satu sama lain. Mungkin, masih terdapat beberapa buah pemikiran manusia yang tergolong moderat dan berorientasi pada sikap keadilan dan keseimbangan. Namun, tetap saja representasi manusia tidak akan terlepas dari beberapa hasil pemikiran lain yang dinilai ekstrem atau tidak seimbang. Bahkan menurut al-Qardlawi, yang mampu menjaga keseimbangan dan kemoderatan segala sesuatu, tanpa terkecuali baik

${ }^{21}$ Ali al-Shabuni, al-Tibyanf 'Ulum al-Qur'an, cet.1, (Jakarta:Daar Al-Kutub Al-Islamiyah, 2003), 118. 
bermateri dan berimmateri, ialah Allah Ta'ala. ${ }^{22}$

Meskipun demikian, Allah Ta"ala tidak menutupi kemampuan manusia untuk dapat mengekspresikan pemikiran dan aksi moderat, tengah-tengah. Di permulaan Al- Qur'an atau kalam-Nya, ada sebuah ajakan terhadap umat manusia untuk berada di ruang paham moderat, tidak selainnya. Telah jelas, kalam-Nya yang berbunyi;

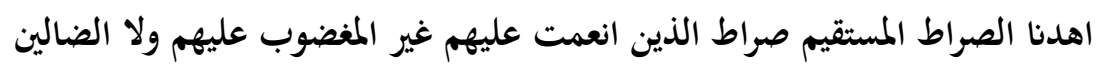

"Tunjukilah kami jalan yang lurus (yaitu) Jalan orang-orang yang telah Engkau beri nikmat kepada mereka; bukan (jalan) mereka yang dimurkai dan bukan (pula jalan) mereka yang sesat." (QS. Al-Faatihah: 6-7)

As-shirat al-mustaqim yang dimaksud ialah jalan atau metode yang moderat dan seimbang. Indikasinya ialah bahwa as-shirat al-mustaqim diilustrasikan denganAyat ke-7 di atas sebagai jalan yang bukan seperti kalangan al-maghdubi 'alaibim dan ad-dhalin. Dengan maksud al-maghdubi 'alaibim ialah kaum yahudi yang ekstrem dalam beragama dan ad-dhalin adalah kalangan nashrani yang berlebihan dalam beribadah, mengartikan $A s$-shirat al-mustaqim sebagai jalan yang moderat, yakni jalan Islam. Singkatnya, agama Islam merupakan minhaj yang berada pada keseimbangan atau moderat. Dalam arti, berada di antara karakter berlebihan dan kecerobohan, ekstrem. ${ }^{23}$

Tidak hanya itu, ungkapan kemoderatan yang berkhitab pada umat Islam sangat jelas pada ayat Al-Quran yang berbunyi:

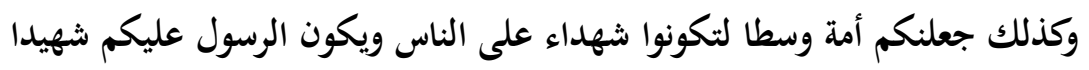

"Dan demikian (pula) Kami telah menjadikan kamu (umat Islam), umat yang adil

${ }^{22}$ Yusuf al-Qardlawi, al-Khasaisal- 'Ammabli al-Islam, cet.2, (Beirut: Mu"assasah al-Risalah,1983), 127.

${ }^{23}$ Tim Penyusun,Bubus Nudwab As |aral-Qur'an al-Karim fiTahai qal-Wasatijah wa DafI al-Guluw, cet. 2, (Arabia Saudi: Kementrian Agama Saudi, 1425), 18-19. 
dan piliban agar kamu menjadi saksi atas (perbuatan) manusia dan agar Rasul (Muhammad) menjadi saksi atas (perbuatan) kamu." (QS. Al-Baqarah: 143)

Dalam komentar al-Zuhaili, wasathan pada ayat ini berarti keadilan atau menjaga keseimbangan. Maka, arti dari umat Islam sebagai umat yang moderat, penengah dan terpilih sebagai saksi ialah bahwa umat ini berpaham sebuah agama yang berkarakter moderat, tidak berat sebelah. Karena agama yang mereka pegang, Islam bukan sebagaimana kalangan sekuler dan materialis, seperti kaum yahudi dan juga bukan di deretan kalangan spiritualis, seperti kaum nashrani. Akan tetapi, Islam yang dipegang umat terpilih tersebut menghimpun hak-hak materi dan immateri atau jasad dan ruh, sebagaimana fitrahnya manusia terbangun dari jasad dan ruh. Sebab itu, umat yang memiliki peluang untuk terpilih sebagai saksi di hari Kiamat ialah umat Islam yang telah merealisasikan karakter keislamannya, yaitu pemikiran dan tindakan moderat bukan ekstrem. $^{24}$

Memang, Islam sendiri selalu mengajarkan keseimbangan pada segala hal, baik yang bersifat materi dan immateri. Artinya, mencakup segala urusan lingkungandan kehidupan manusia. Contoh kecil dari sebuah keseimbangan ialah bahwa kadar air yang Allah Ta'ala turunkan di bumi terukur sesuaikehidupan, tidak lebih dan tidak kurang. ${ }^{25}$ Dari sini, bisa ditarik

${ }^{24}$ Wahbah al-Zuhaili, at-Tafsir al-Munifial-'Aqidah wa al-Syariah wa al-Manhaj, vol. 2, cet.2, (Damaskus: Dar alFikr al-Ma'ashir, 1418),9.

25 Jika menimbang segala penciptaan alam semesta dan seisinya, sebenarnya keseimbangan segala sesuatu

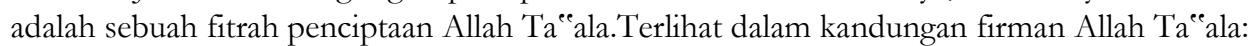

"Dan Kami turunkan air dari langit menurut suatu ukuran; lalu Kami jadikan air itu menetap dibumi, dan sesunggubnya Kami benar-benar berkuasa menghilangkannya."(QS.Al-Mu“ minuun:18)

"Dan Kami telah menghamparkan bumi dan menjadikan padanya gunung-gunung dan Kami tumbubkan padanya segala sesuatu menurut ukuran.” (QS. Al-Hijr: 19)

Ukuran dalam kedua ayat ini tidak diartikan dengan sebuah ukuran yang berlebihan atau bahkan yang kekurangan. Melainkan, menurut syekh al-Qardlawi, diartikan dengan sebuah ukuran yang sesuai dengan kebutuhan, tidak lebih dan tidak kurang, atau tengah-tengahnya.

Pada satu ayat surat Al-Mu'minun di atas, air yang Allah Ta ${ }^{e e}$ ala turunkan sesuai kebutuhan hidup. Jika 
kesimpulan bahwa Islam tidak pernah mengajarkan sesuatu yang ekstrem, berat sebelah, apalagi berujung pada intoleran. Ajaran yang disampaikan Islam sebenarnya adalah ajaran yang menggiring manusia agar tidak melakukan sikapsikap yang berbanding terbalik dengan namanya, yakni, salam atau damai. Jadi, ketika ada seorang narator yang mengatasnamakan Islam dengan bawaan intoleran, berlebih-lebihan, dan mudah menyalahkan, sebenarnya ia justru jauh dari nilai Islam. Karena sebagaimana namanya, Islam lebih bertendensi pada sikap tawasut atau yang bersentuhan dengan sikap-sikap damai atau salam.

\section{ETOS PERDAMAIAN DALAM PANCASILA: TRISILA DI MUKA CERMIN AL-QUR'AN}

Secara umum, ideologi merupakan sekumpulan peraturan baik berupa ide maupun gagasan dan kepercayaan yang digunakan untuk mengatur kehidupan di bidang tertentu. Bersifat mengikat dan sistematis. Sedangkan secara harfiah, ideologi berasal dari bahasa Yunani. Terdiri dari dua kata dasar yang tersusun dan jadi istilah ideologi. Dua kata tersebut adalah ideos atau ideo dan logos atau logie. Ideo berarti ide atau juga gagasan dan pemikiran. Sedang logie berarti ilmu atau logika. Maka, pengertian bahasa mendefinisikan ideologi sebagai segenap pemikiran dan ilmu yang ditujukan untuk mencapai tujuan dan angan-angan masyarakat dalam aspek ide tertentu. ${ }^{26}$

Dalam konteks Indonesia, Pancasila diposisikan sebagai landasan idiil karena dengan Pancasila, bangsa Indonesia akan menggapai tujuannya, yaitu masyarakat adil, makmur material dan spiritual berdasarkan ideologi Pancasila.

\footnotetext{
Ia berkehendak, niscaya Ia bisa menghilangkannya. Pada satu ayat surat Al-Hijr juga, segala sesuatu yang Allah Ta ae ala tumbuhkan terukur sesuai hukum ukuran keseimbangan-Nya. Sedangkan, kosa kata moderat, keadilan dan keseimbangan memiliki titik persamaan, yaitu tidak berat ke kanan ataupun ke kiri. Dalam arti, mengambil jalan tengah. Jadi, keseimbangan dan pola pikir tengah-tengah, moderat adalah sebuah fitrah penciptaan Allah Ta ${ }^{e e}$ ala yang hendaknya terlestari. Lihat Yusuf al-Qardlawi, Ri'ayjat al-Bi $>$ ab fi Syariat al-Islam,cet.1, (Mesir:DarasSyuruq,2001),152-153.

26 "Pengertian Ideologi", RomaDecade,https://www.romadecade.org/pengertian-ideologi/\#
} 
Sebagai filsafat dasar negara, Pancasila merupakan cita-cita luhur dan landasan bangsa Indonesia yang secara logik tidak boleh dikesampingkan. Bahkan dari aspek lain, Pancasila berperan sebagai kepribadian bangsa Indonesia. ${ }^{27}$

Pandangan hidup suatu bangsa adalah sesuatu yang tidak dapat dilepaskan dari kehidupan bangsa yang bersangkutan. Bangsa yang tidak memiliki pandangan hidup adalah bangsa yang tidak memiliki jati diri dan kepribadian. Sehingga dengan mudah akan terombang-ambing pada saat-saat menghadapi berbagai tantangan dan pengaruh yang datang. Sebagaimana keterangan sebelumnya, Pancasila adalah pandangan hidup bangsa Indonesia. Pancasila ialah jati diri dan kepribadian bangsa yang merupakan kristalisasi dari nilai-nilai yang hidup dalam budaya masyarakat Indonesia sendiri. ${ }^{28}$

Ideologi bangsa ini dirumuskan oleh pakar yang datang dari berbagai etnis yang berbeda. Karena memang sebagaimana dapat dilihat, Indonesia adalah negara yang majemuk. Indonesia adalah negara yang berpenduduk Muslim terbesar di dunia. 88\%-sekitar kurang lebih 175 juta-penduduknya diklasifikasi sebagai pemeluk Islam. Yang menarik dari data ini adalah meskipun pemeluk Islam mendominasi di negeri ini, negeri ini tidak menghendaki Islam sebagai ideologi politik yangmengintegrasikan umat Islam dalam cakupan konteks nasional yang lebih luas. Negeri ini justru mencomot Pancasila sebagai ideologi. Ideologi yang mengemas seluruh perbedaan etnis di dalamnya. Ideologi yang mencakup seluruh golongan di dalamnya. ${ }^{29}$

Sebagaimana yang sudah disinggung di atas, Pancasila adalah hasil perenungan yang mendalam dari para pendiri bangsa ini. Bukan sekedar buah

\footnotetext{
${ }^{27}$ Sunoto, Mengenal Filsafat Pancasila, 99.

${ }^{28}$ Tim Penyusun MKD IAIN Sunan Ampel, Pancasila dan Kewarganegaraan, 164

${ }^{29}$ Nur Muthmainnah, "Tafsir Pancasila: Sebuah Telaah Nilai-Nilai Islam Dalam Al-Qur"An”, JurnalStudi AlQur'an, Vol. 6., No.1 (2010), 28.

At-Turäs: Jurnal Studi Keislaman

E-ISSN: 2460-1063, P-ISSN: 2355-567X

Volume 7, No. 1, Januari-Juni 2020
} 
analisis, tapi lebih dari itu, ia adalah hasil rekonstruksi pemikiran yang tidak bisa digapai oleh sembarang orang. Ia lahir melalui musyawarah yang panjang. Perdebatan yang mempertaruhkan keberlangsungan bangsa dalam ringkup keberagamannya. Melalui penghapusan piagam Jakarta, agaknya mudah dimengerti bahwa negara yang punya sumbangsih besar atas agama tersebut selaras dan klop. Agama, adat, dan budaya di negeri tersebut bisa dan mau diserasikan. Pemeluknya yang mayoritas Islam, memilih hidup damai dan berdampingan dengan kelompok lain yang tidak satu keyakinan, dan Indonesia dengan seluruh keanekaragamannya tidak menampik perbedaan.

Sebelum Pancasila digemakan dengan bunyi yang bertahan sampai hari ini, ada tujuh kata yang condong pada umat Islam, yakni tujuh kata dalam piagam jakarta yang bunyinya "Ketuhanan dengan kewajiban menjalankan syariat Islam bagi pemeluk-pemeluknya." Selain kata ketuhanan, kata yang lain dihapuskan setelah melalui masa-masa kritis, tepatnya pasca kemerdekaan, 18 Agustus 1945. "wakil- wakil umat Islam menyetujui usul penghapusan anak kalimat tersebut dari Pancasila dan batang tubuh UUD 1945. Namun pada sila pertama. Kata "Ketuhanan" diberi tambahan atribut kunci, sehingga menjadi "Ketuhanan Yang Maha Esa". ${ }^{30}$ Dalam konteks yang lain, kata "Tuhan yang Maha Esa" diusulkan oleh K.H.A. Wahid Hasyim. Karena memang sebenarnya, sila-sila dalam Pancasila sinkron dengan ajaran Islam. Sinkron dengan ayat yang terdapat dalam Al-Qur"an.

\section{KEBEBASAN BERAGAMA MENGEMAS KEBERAGAMAN: ISLAM DAN PANCASILA}

Islam menganut paham monoteisme. Menganut paham menyembah satu Tuhan saja. Terbukti dari ayat Al Qur"an yang bunyinya:

${ }^{30}$ Ibid., 29. 


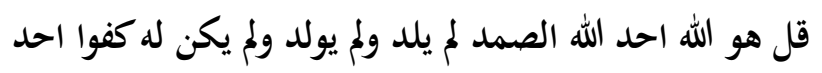

"Katakanlah: "Dia-lah Allah, yang Maha Esa. Allah adalah Tuban yang kepada-Nya segala sesuatu bergantung. Dia tiada beranak dan tidak pula diperanakkan, dan tidak ada seorangpun yang setara dengan Dia." (QS. AlIkhlas: 1-4)

Ajaran menyembah satu Tuhan, dan tidak menyekutukanNya dengan yang lain adalah ajaran paling penting dalam risalah Nabi Muhammad Saw. AlShabuni dalam tafsirnya, memulai penafsirannya atas ayat tersebut dengan menghadirkan perbedaan pendapat ulama' atas sababal-nuzul. Adasetidak- tidaknya tiga perbedaan yang dimunculkan Al Shabuni. Selanjutnya, Muallif kitab tafsir kontemporer memulai tafsirnya dengan klasifikasi surat, bedah kalimat, penyebutan sabab al-nu₹ul, lalu mulai masuk area tafsir. Tafsiranyang dituliskan Al Shabuni menginformasikan bahwa saat itu Muhammad diperintah untuk mendeklarasikan Tuhannya sebagai apa yang ia sembah, yang tidak ada sekutu atau yang menyerupai-Nya. Dan hanya Dia (Tuhan Muhammad) satu- satunya. Tak ada yang menyerupaiNya dari semua aspek, baik af'ał, sifar, maupun dz̧at. Bukan pula berarti sama dengan kaum Nasrani yang menyembah tiga Tuhan, atau seperti orang musyrik yang julah Tuhannya berbilang. ${ }^{31}$

Jelas sekali dalam Islam, penganutnya harus mengakui satu Tuhan saja. Hal ini rasanya sudah serasi dengan Pancasila yang membunyikan sila pertama dengan "Ketuhanan yang Maha Esa". Meskipun hakikatnya, kemunculan Tuhan yang bermacam-macam tersebut merupakan gambaran dari kemampuan manusia masing-masing dalam upaya menghadirkan satu bentuk kekuatan di luar dirinya dalam memberi pertolongan kepadanya. Namun, Dengan ketuhanan yang MahaEsa, Pancasila mengajarkan setiap manusia Indonesia percaya pada Tuhan yang Maha Esa. Sesuai dengan agama dan keyakinan

31 Muhammad Ali al-Shabuni, Safwat al-Tafair, vol. 3, cet.1, (Kairo: Dar al-Shabuni,1997), 594. 
masing-masing. ${ }^{32}$

Islam pun mengajarkan kebebasan beragama yang tersirat dalam keterangan di atas. Artinya Pancasila ataupun Islam sama-sama mengajarkan manusia untuk tidak berpaham atheisme, melainkan kepercayaan pada Tuhan yang Maha Esa sesuai kepercayaan masing-masing, dengan tanda kutip bebas beragama. hal ini tercover dalam surat Al-Kafirun yang berbunyi:

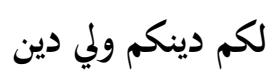

"Untukmu agamamu, dan untukkulah, agamaku." (QS. Al-Kafirun: 6)

Bukan satu kali Al-Qur"an membunyikan ayat dengan konotasi serupa, ayat dengan ajaran tidak memaksa seseorang masuk dalam Islam atau kebebasan beragama. Di ayat yang lain, Al Qur ${ }^{\text {ee } a n ~ m e n g i n f o r m a s i k a n ~ b a h w a ~}$ kebebasanberagama itu ada. Bunyinya:

$$
\text { لا إكراه في الدين قد تبين الرشد من الغي }
$$

"Tidak ada paksaan dalam beragama (Islam); sesunggubnya telah jelas jalan yang benar dari jalan yang sesat." (Q.S Al Baqarah: 256)

\section{KEMANUSIAAN QUR'ANI DALAM ETOS PANCASILA}

Setiap orang hakikatnya punya jiwa kemanusiaan. Demikian pula bangsa Indonesia. Bangsa Indonesia memilih caranya sendiri dalam mengusung konsep kemanusiaan, yakni dengan adil dan beradab sebagaimana disebutkan dalam sila ke dua Pancasila. Perbuatan ini dapat diperlihatkan dalam perbuatan manusia di Indonesia yang tidak hanya mementingkan kebutuhan jasmani, tapi juga mementingkan aspek rohani. Pun, tidak hanya mementingkan diri sendiri, ia juga memperhatikan aspek organisasi, kepentingan masyarakat. Hal ini dilakukandalam rangka pengabdian kepada Tuhan yang Maha Kuasa. Contoh

\footnotetext{
32 Sunoto, Mengenal Filsafat Pancasila, 76 dan 61.
} 
nyata-pun diberikan secara langsung oleh masyarakat Indonesia, salah satunya dituangkan dalam bentuk kesenian. Antara lain, Wayang, ludruk, ceritera, dan lain sebagainya yang selalu menonjolkan nilai-nilai kemanusiaan dan bagaimana nilai kemanusiaan tersebut dijunjung tinggi. Misal, para satria digambarkan sebagai orang yang banyak mendedikasikan dirinya. Ia menolong orang lain yang membutuhkannya. Berlaku jujur, dan beratribut seluruh sifat terpuji yang ada. Dengan semboyan kuat paring pangan wong keluwen, paring teken wong kelunyon, paring sandang wong kawudan, paring payung wong kodanan. ${ }^{33}$

Ajaran soal kemanusiaan tersebut telah dilakukan dan dikumandangkan oleh bangsa Indonesia. Terbukti dari kebiasaan masyarakat Indonesia menjenguk orang sakit dan memberikan bantuan pada orang yang membutubkan telab dilaksanakan masyarakat Indonesia sampai sekarang. Sebaliknya, perbuatan yang melanggar dan tidak sesuai dengan ajaran kemanusiaan tersebut akan dipukul mundur oleb bangsa dengan ideologi Pancasila ini. $^{34}$ Ajaran kemanusiaan ini selaras dengan salah satu ayat dalam al-Qur'an yang berbunyi;

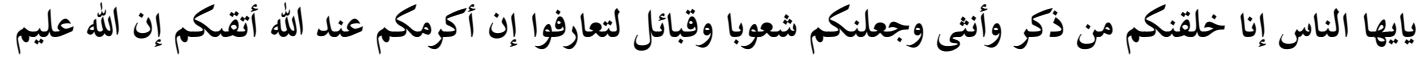

${ }^{33}$ Menurut redaksi yang lain, semboyan tersebut lahir di zaman Sunan Derajat. Info ini setidaknya lebih jelas bila dan siapa yang melahirkan kalimat dengan pesan sejuk tersebut. Hanya saja, meski konteksnya samasama menyoal kemanusiaan, lafadznya berbeda. Menurut beberapa redaksi, kalimat yang dipesankan Sunan Derajat berbunyi "wehono teken marang wong wuto, wehono pangan marang wong kang keluwen, wehono payung marang wong kaudanan, lan wehono sandang maran wong kang kawudan."Wehono teken marang wong kang wuto secara harfiyah berarti, berilah tongkat kepada orang yang terpeleset dan buta. Secara makna, ia bermakna, berilah ilmu agar orang menjadi pandai dan tidak melakukan kesalahan. "wehono pangan marang wong kang keluwen" secara harfiah berarti, berikan makan kepada orang yang kelaparan. Secara makna ia berarti, sejahterakan kehidupan masyarakat. "wehono sandang marang wong kang kawudan" secara literal ia berarti, berikan payung kepada orang yang kehujanan. Secara makna, ia justru bermakna, ajari soal kesusilaan pada orang yang sudah putus rasa malunya. "wehono payung marang wong kang kaudanan" secara bahasa berarti, berikan payung pada orang yang kehujanan. Secara makna ia dapat diartikan sebagai, beri perlindungan pada orang yangmenderita. Empat ajaran sunan derajat ini tertera di makamnya hingga hari ini. Untuk diamalkan para santrinya, dan dibaca oleh manusia lainnya. Empat ajaran kemanusiaan ini pun masyhur di kalangan masyarakat setempat. Lihat Bahari, "Perahu Pecah, Sunan Drajat Diselamatkan Ikan Cucut", terakhir dipost Januari 05, 2018, https://radarjogja.jawapos.com/2018/06/05/perahu-pecah-sunan-drajat-diselamatkan-ikan-cucut/.

34 Sunoto, Mengenal Filsafat Pancasila, 76-77.

At-Turäs: Jurnal Studi Keislaman

E-ISSN: 2460-1063, P-ISSN: 2355-567X

Volume 7, No. 1, Januari-Juni 2020 
"Hai manusia, Sesunggubnya Kami menciptakan kamu dari seorang laki-laki dan seorang perempuan dan menjadikan kamu berbangsa - bangsa dan bersukusuku supaya kamu saling kenal-mengenal. Sesunggubnya orang yang paling mulia di antara kamu di sisi Allah ialah orang yang paling taqwa di antara kamu. Sesunggubnya Allah Maha Mengetahui lagi Maha Mengenal." (Q.S. AlHujuraat: 13)

Benang merah yang bisa ditarik dalam ayat ini adalah lita'arafu. Saling mengenal. Sikap saling mengenal adalah perintah yang berkonotasi bahwa dalam Islam ada anjuran untuk berdialog dan mengenal satu sama lain. Ketika ini terjadi, dialog dikedepankan, komunikasi lancar, maka kemungkinan terjadinya kesalahpahaman, bentrok antar masyarakat, dan sebagainya akan sulit dihadirkan.

Nilai kemanusiaan juga dibunyikan dalam narasi lain pada ayat yang berbeda:

$$
\text { وإذ قال ربك للملائكة إنى جاعل في الأرض خليفة }
$$

"Ingatlab ketika Tuhanmu berfirman kepada para Malaikat: "Sesunggubnya Aku hendak menjadikan seorang khalifah di muka bumi." (Q.S. Al Baqarah: 30)

Ayat ini merupakan firman Allah Ta"ala pada saat hendak melantik nabi Adam, manusia pertama sebagai khalifah di muka bumi. Bahkan, menafsiri kata "khalijah" pada ayat di atas tidak hanya berarti nabi Adam, melainkan berarti anak turunnya juga, yaitu manusia. Alasan paradigma yang demikian ialah bahwa yang hanya dapat menjadi lentera yang dapat menampakkan cahaya sifat- sifat Allah Taeala adalah manusia. Cahaya sifat-sifat-Nya dapat bersinar dibumi melalui wujudnya keadilan, perbuatan baik dan belas kasih. Sedangkan, sifat-sifat yang demikian hanya tersusun dalam diri manusia, bukan hewan atau malaikat. Karena sifat-sifat ini merupakan sifat-sifat kemanusiaan. Karenanya, penciptaan manusia merupakan khalifah yang berperan menampakkan 
eksistensi Allah Ta"ala sebagai Tuhan di muka bumi. ${ }^{35}$

\section{KEISTIMEWAAN DEMOKRASI INDONESIA: SILA KE-EMPAT DAN PERADABAN ISLAM}

Demokrasi khas Indonesia dapat ditemukan di Pancasila, tepatnya di sila ke-empat. Melalui pendekatan kosmologik, sila ke-empat yang berbunyi "Kerakyatan yang dipimpin oleh hikmat kebijaksanaan dalam permusyawaratan/perwakilan" bernilai kerakyatan dan musyawarah mufakat. Dalam sila ini, secara eksplisit dibunyikan istilah kerakyatan bukan demokrasi. Di samping itu, sila ini ditegaskan lagi dengan membunyikan kata-kata yang dipimpin oleh hikmat kebijaksanaan dalam permusyawaratan/perwakilan. Dari kedua unsur ini, menandakan bahwa perinsip kerakyatan yang dibunyikan dalam sila ini tidak seperti sistem demokrasi liberal yang berprinsip pada kebebasan mutlak individu dan sistem mayoritas. Melainkan, sistem demokrasi yang terkandung dalam sila ini ialah musyawarah mufakat. Dalam artian bahwa musyawarah yang dikandung dalam sila ini ialah musyawarah kekeluargaan. ${ }^{36}$ Musyawarah yang demikian berbeda dengan musyawarah pada umumnya yang hanya mengambil keputusan dari suara terbanyak. Karena dalam memecahkan permasalahan, musyawarah kekeluargaan melalui saling dialog, saling melontarkan pengertian dan beradu argumen yang kemudian keputusan bersama diambil dari mufakat dalam suasana kekeluargaan. ${ }^{37}$

Selain itu, cita rasa hikmat-kebijaksanaan hanya dapat terwujud dalam sistem musyawarah kekeluargaan. Sistem yang demikian juga sejajar dengan esensinilai perikemanusiaan, persatuan dan keadilan. Nilai esensi dalam sila ini

\footnotetext{
${ }^{35}$ Hasan bin Muhammad al-Naisaburi, Gharail al-Qur'an wa Raghaib al-Furq\} ${ }^{\prime} \gg$, vol.2, cet.1, (Lebanon: Daar alKutub al-Ilmiyah, 1996), 216.

36 Sunoto, Mengenal Filsafat Pancasila, 74.

37 Afkar, Kritik Ideologi Radikal, 421-422.

At-Turäs: Jurnal Studi Keislaman

E-ISSN: 2460-1063, P-ISSN: 2355-567X

Volume 7, No. 1, Januari-Juni 2020
} 
berdasarkan penjelasan di atas, sangat selaras dengan bunyi ayat:

$$
\text { وشاورهم في الأمر }
$$

"Dan bermusyawaratlah dengan mereka dalam urusan itu." (QS. Ali Imran:

Ayat ini membunyikan prinsip musyawarah sebagai media memecahkan permasalahan. Secara eksplisit, ayat ini membunyikan perintah musyawarah. Hal ini mengindikasikan bahwa ayat ini mendukung sistem demokrasi dan menolak terwujudnya hak veto. Di samping itu, memperjelas dalam tafsirnya bahwa sistem yang dikehendaki dalam prinsip musyawarah yang dibunyikan ayat ini ialah bukan sebagai media yang dapat melahirkan perselisihan. Melainkan, sistem musyawarah yang dimaksud adalah musyawarah dengan ketenangan, saling mendengar argumen satu sama lain dan saling berdialog, serta saling mengunggulkan argumen yang terdapat sisi kemaslahatan dan faedah. Oleh karenanya, musyawarah menurut penafsiran al-Maraghy terhadap ayat ini ialah sistem musyawarah yang dapat melahirkan kemufakatan bagi para musyawir dalam menentukan satu tindakan. Sistem musyawarah yang demikian sesuai dengan musyawarah kekeluargaan yang menjadi esensi dalam sila keempat. Serta, sesuai dengan sistem demokrasi yang berciri khas bagi sistem pemerintahan Negara Indonesia. ${ }^{38}$

Selain ayat di atas, pada ayat lain pula yang berbunyi:

$$
\text { والذين استجابوا لرجم واقاموا الصلوة وامرهم شورى بينهم ومما رزقنهم ينفقون }
$$

"dan (bagi) orang-orang yang menerima (mematubi) seruan Tubannya dan mendirikan shalat, sedang urusan mereka (diputuskan) dengan musyawarah antara mereka; dan mereka menafkabkan sebagian dari rezki yang Kami berikan kepada mereka." (QS. Al-Syuraa: 38)

38 Ahmad bin Mustafa al-Maraghi,Tafsiral-Maraly $)$, Vol. 4, (Mesir: Mustafa al-Babi, 1946), 113-114. 
Menjelaskan bahwa karakter kaum dalam mencetuskan dan mendudukkan suatu permasalahan ialah dengan permusyawaratan. Bahkan menurut al-Maraghi, Rasulullah SAW tidak mempergunakan kewenangannya atau hak veto-nya dalam mendudukan segala poblematika selain hukum-hukum syari’ah. Ia seringkali mengadakan permusyawaratan bersama para shahabat.

Akhirnya, permusyawaratan menjadi media pengambilan keputusan yang dilestarikan oleh peradaban umat Islam dari masa ke masa. Dimulai pertamakali secara mandiri setelah wafatnya Rasulullah SAW, yaitu yang dilakukan para shahabat dalam rangka penentuan khilafah setelah Rasulullah SAW. Hal yang demikian karena musyawarah sendiri memiliki suatu keistimewaan. Menurut Ibn al-Araby, musyawarah yang seperti dilakukan Rasulullah SAW dapat mempersatukan sekelompok orang-orang. Selain itu, musyawarah juga merupakan sebuah alat untuk mengasah dan mempertajam pemikiran atau akal. Serta, merupakan media pengantar kepada kebenaran. ${ }^{39}$

\section{KESIMPULAN}

Konflik yang meruntuhkan perdamaian selalu ramai diperbincangkan. Keberagaman adalah sebuah fenomena dan tantangan yang selalu siap menerima perbedaan pemikiran dan sikap. Namun, Indonesia yang lekat dengan keberagaman dikenal sebagai negara yang mampu mengelolanya dalam keharmonisan.

Negara Pancasila ini pantas menjadi cerminan dunia. Meskipun dengan penduduk muslim terbanyak, Islam di Indonesia hidup tentram dan damai bersama agama lain dan ideologi yang bukan bernama Islam, tetapi Pancasila. Melalui konstruksi demikian, Pancasila yang menduduki sebagai ideologi dan

${ }^{39}$ Ibid., vol. 25, 52.

At-Turäs: Jurnal Studi Keislaman

E-ISSN: 2460-1063, P-ISSN: 2355-567X

Volume 7, No. 1, Januari-Juni 2020 
jiwa seluruh bangsa Indonesia, mengindikasikannya juga pantas dihadirkan di dunia internasional. Menurut penelusuran para intelektual Islam, Pancasila tidak terlepas dari roh Islam, sebuah agama yang berkarakter wasathiyah. Bahkan, selarasdengan ayat-ayat Al- Qur'an.

Terdapat tiga prinsip besar dari etos Pancasila yang patut menjadi role model bagi perdamaian dunia. Tiga prinsip ini sebagaimana perasan Pancasila, dengan sebutan Trisila. Penulis pula menguatkan tiga prinsip ini dengan ayatayat Al-Qur'an. Pertama, Pancasila dapat mengelola keberagaman melalui konsep kebebasan beragama. Kedua, Pancasila menjunjung tinggi nilai kemanusiaan sebagaimana Islam. Ketiga, Pancasila memiliki sistem demokrasi yang khas, yaitu sistem pemerintahan yang mengutamakan musyawarah mufakat atau kekeluargaan, bukan berprinsip pada kebebasan mutlak individu atau sistem mayoritas. 


\section{DAFTAR PUSTAKA}

"Islam Nusantara: Akulturasi Islam Dan Budaya Lokal". Hikam.Id, Terakhir Dipost September 24, 2019, https://hikamadress99.blogspot.com/2019/09/islam-nusantaraakulturasi-islam-dan.html

"Majelis Al-Hukamaee", Quraishshihab.Com, Terakhir Dipost November 25, 2019, https://quraishshihab.com/article/majlis-al-hukama/

"Pengertian Ideologi", Romadecade, https://www.romadecade.org/pengertianideologi/\#

Afkar. (2018.) Kritik Ideologi Radikal. Cet.1. Kediri: Lirboyo Press.

Bahari, "Perahu Pecah, Sunan Drajat Diselamatkan Ikan Cucut", Terakhir Dipost Januari 05, 2018, https://radarjogja.jawapos.com/2018/06/05/perahu-pecah-sunandrajat-diselamatkan-ikan-cucut/.

Choironi, Alvin Nur, "Quraish Shihab Hadiri Deklarasi Abu Dhabi Bersama Syekh Al Azhar Dan Paus Fransiskus", Islami.Co, Terakhir Dipost Februari 06, 2019, https://islami.co/quraish-shihab-hadiri-deklarasiabu-dhabi-bersama-syekh-al-azhar-dan-paus-fransiskus/

Junaid, Hamzah. (2013). "Kajian Kritis Akulturasi Islam Dengan Budaya Lokal”, Sulesana, 8(1).

Maraghi, Ahmad Bin Mustafa Al-. (1946). Tafsiral-Maraghi. Vol 4. Mesir: Mustafa Al-Babi.

Muhammad, Ren, "Islam Tanpa Indonesia", Alif.Id, Terakhir Dipost Juli 08, 2019, https://alif.id/read/ren-muhammad/islam-tanpa-indonesia$\underline{\mathrm{b} 220816 \mathrm{p} /}$

Muthmainnah, Nur. (2010). "Tafsir Pancasila: Sebuah Telaah Nilai-Nilai Islam Dalam Al-Qur'an”, Jurnal Studi Al-Qur 'An, 6(1).

Naisaburi, Hasan Bin Muhammad Al- (1996). Gharaib Al-Qur'an Wa Ragbaib AlFurqan. Cet.1. Beirut. Lebanon: Daar Al-Kutub Al-Ilmiyah.

Qardlawi,Yusuf Al-. (1983). Al-Khasais Al-'Ammah Li Al-Islam. Cet. 2. Beirut: Mu"Assasah Al- Risalah.

Qardlawi,Yusuf Al-. (2001). Ri'ayat Al-Biahbil Syariat Al-Islam. Cet. 1. Mesir: Dar AsSyuruq. 
Rozak, Abdul. (2008). "Komunikasi Lintas Agama: Modal Sosial Pembentukan Masyarakat Sipil", JURNAL D AKW AH, 9(1).

Shabuni, Ali Al-. (2003). Al-Tibyan Fi 'Ulum Al-Qur'an. Cet.1. Jakarta: Daar AlKutub Al-Islamiyah.

Shabuni, Muhammad Ali Al-. (1997). Shafwat Al-Tafasir. Vol.3. Cet.1. Kairo: Dar Al-Shabuni.

Shihab, Alwi,. (t.th). Islam dan Kebhinekaan. Jakarta: Gramedia Pustaka Utama.

Sunoto. (1995). Mengenal Filsafat Pancasila. Yogyakarta: Hanindita Graha Widya.

Tim Penyusun MKD IAIN Sunan Ampel. (2013). Pancasila dan Kewarganegaraan. Surabaya: UIN Sunan Ampel Press.

Tim Penyusun. (1425). BubusNudwah Astar Al-Qur'an Al-Karim Fi Tahqiq Al-Wasatiyah Wa Daf'i Al-Guluw. Cet. 2. Arabia Saudi: Kementerian Agama Saudi.

Wahyudi, Chafid. (2015). "Etika Publik Sebagai Ruang Dialog Agama", HIKMATUNA, 1(1).

Zada, Khamami, Dkk. (2008). Prakarsa Perdamaian: Pengalaman Dari Berbagai Konflik Sosial Kapital. Jakarta: PP Lakpesdam NU.

Zuhaili, Wahbah Al-. (t.th). Al-Fiqh Al-IslaMi Wa Adillatuh. Cet. 4. Damaskus: Dar Al-Fikr.

Zuhaili, Wahbah Al-. (t.th). At-Tafsir Al-Munir Al-'Aqidab Wa Al-Syariah Wa AlManhaj. Cet. 2. Damaskus: Dar Al-Fikr Al-Ma’ashir, 1. 